\title{
Erratum zu: Ein Matrix-Berechnungsmodell zur Simulation und schnellen Berechnung der mittleren Temperaturdifferenz mehrgängiger Kreuzstrom-Plattenwärmeübertrager
}

\author{
Torben Möller ${ }^{1}$ - Olaf Strelow ${ }^{2}$
}

Online publiziert: 11. Juli 2017

(C) Springer-Verlag GmbH Deutschland 2017

\section{Erratum zu:}

Forsch Ingenieurwes

DOI 10.1007/s10010-017-0213-5

Der Originalbeitrag wurde hinsichtlich der Darstellung von Gleichung (24) und der URL von Literaturreferenz 4 korrigiert.

Die Online-Version des Originalartikels ist unter doi: 10.1007/ s10010-017-0213-5 zu finden.

$\triangle$ Torben Möller moeller@gam.de

1 Entwicklung/Technik Wärmeübertrager, G.A.M. HEAT GmbH, Mittelstrasse 13, 57339 Erndtebrück, Deutschland

2 Institut für Thermodynamik, Energieverfahrenstechnik und Systemanalyse, Technische Hochschule Mittelhessen, Gießen, Deutschland 